\title{
A new correlation for water saturation calculation in gas shale reservoirs based on compensation of kerogen-clay conductivity
}

\author{
Ali Kadkhodaie* and Reza Rezaee \\ Department of Petroleum Engineering, Curtin University, Perth, Western Australia
}

\begin{abstract}
Determination of water saturation in gas shale reservoirs is a very challenging issue due to the incomplete understanding of the non-Archie components. Kerogen and clay content are the two main factors controlling the conductivity of gas shales and resistivity log responses. The presence of clays as conductive materials causes excessive conductivity for the rock that result in an overestimation of water saturation calculation. On the other hand, the presence of solid kerogen has an opposite effect to clays and causes reduction of rock conductivity and thus underestimation of water saturation.

In this research, attempts have been made to develop an effective equation for water saturation determination in gas shale reservoirs based on compensation of kerogen and shale conductivities. The new equation is able to handle both high and low conductivity components. The proposed approach makes one step ahead towards reducing uncertainty in the petrophysical evaluation of gas shale reservoirs. Being independent of formation water resistivity and Archie parameters are of the important and effective aspects of the introduced equation in water saturation calculation of gas shale reservoirs.

Finally, the kerogen-clay compensation equation has successfully been applied to the determination of water saturation in the Goldwyer shale formation, Canning basin, Western Australia.
\end{abstract}

Keywords: Water saturation, gas shale reservoirs, kerogen, shale resistivity, total organic carbon

\section{Introduction}

Water saturation $(\mathrm{Sw})$ is a key and a sensitive parameter for hydrocarbon reserve estimation and any overestimation or underestimation will affect economic evaluations of reservoirs and field development plans. Gas shale reservoirs host considerable amounts of natural gas trapped in the form of free gas and

\footnotetext{
* Corresponding author: Tel/Fax: +61892669366

Email addresses: ali.kadkhodaie@ curtin.edu.au (Ali Kadkhodaie), r.rezaee@curtin.edu.au (Reza Rezaee)
} 
adsorbed gas within their pore space. Petrophysical evaluation of rock properties in gas shales is associated parameters need to be introduced in almost all equations (e.g. Zuber et al., 2002; Sondergeld et al., 2010; Kale, et al., 2010; Mullen, 2010; Ramirez et al., 2011; Ambrose et al., 2012; Rezaee, 2015). The complex pore and organic matter network together with adsorbed gas to the surface of kerogen affect the logging tool responses needing to take them into consideration in petrophysical calculations.

In this regard, accurate determination of water saturation plays a very important role in economic evaluations of gas shales. Investigation of the methods of water saturation determination in gas shale reservoirs has received less attention in the literature in comparison to porosity. Non-Archie rules control the fluids saturation of gas shales since clay and kerogen are two additional components affecting water saturation. On the other hand, the key unknown parameter in water saturation determination is formation water resistivity. The complex interaction between the different mineral and fluid components causes local conductivity barriers in a shaly gas reservoir resulting in a variable range of water resistivities. In this context, a highly variable range of water salinities from a few thousand to a few hundred thousand ppm have been reported throughout a single gas shale formation (e.g. Luffel et al., 1992; Martini et al., 2008 and Zuber et al., 2002). Accordingly, setting a constant value for formation water resistivity will result in uncertain estimation of water saturation.

Unlike conventional reservoirs, there is no feasible well testing method to collect formation water sample from shales. Besides, water samples produced from gas shales are always not representative of the resistivity of the rock due to the mixing of produced flow back water and free water present in natural fractures (Wang and Reed, 2009, Bust et al., 2013).

Actually, a shale gas reservoir is a mixture with different contributions of solid clay, solid kerogen, connate water, free water, clay bond-water, free gas and adsorbed gas to the surface of kerogen. What a resistivity tool measures is a reflection of constituent mineral and fluids of gas shales.

The current research proposes an effective equation for quantification of water saturation in shale gas reservoirs which is independent of water resistivity and Archie parameters. It accounts for conductivity increase or decrease by the presence of conductive or insulator components within shale in water saturation determination equation. 


\section{Developing a new formula for $\mathrm{Sw}$ determination}

The new equation introduced is a derivation of Archie's law developed for clean sand formations (Archie, 1942). According to Archie's law, the ratio of the conductivity of formation water (brine) to the conductivity of a rock fully saturated with that water is a constant value called formation factor (Fig. 1a).

$$
F=\frac{C_{w}}{C_{o}}
$$

or in terms of resistivity formation factor can be expressed as follows:

$F=\frac{R_{o}}{R_{w}}$

Rearranging equation 1 and solving it for $C_{o}$ gives:

$C_{o}=\frac{C_{w}}{F}$

Eq. 3 can be considered for hydrocarbon zone by introducing water saturation to the formula and replacing $C_{o}$ by $C_{t}$ as follows:

$C_{t}=\frac{C_{w}}{F} S_{w}{ }^{n}$

Eq. (4) can be rearranged as:

$$
R_{t} \cdot S_{w}{ }^{n}=F \cdot R_{w}
$$

if $F$ in Eq. (5) is substituted with $F$ in Eq. (2) then:

$$
R_{t} \cdot S_{w}{ }^{n}=R_{o}
$$

Eq. (6) can be rearranged as:

$$
R_{t}=\frac{R_{o}}{S_{w}^{n}}
$$

Eq. (7) is actually an alternative way for representation of the popular Archie formula in a clean formation which is independent of pore water resistivity and Archie parameters (quick look formula). In shaly 
formations, the presence of clay causes excessive conductivity (Fig. 1). In this regard, some other equations proposed for correction of shale effect or conductivity increase in water saturation equation (e.g. Simondoux, 1963; Waxman and Smith, 1968; Pouon and Leveaux, 1971; Clavier and Coates, 1984).

A gas shale reservoir can be treated as a high clay content and organic-rich siliciclastic or carbonate rock. In this context, all equations used for determination of water saturation in shaly formations can be considered after applying necessary corrections for the presence of organic matter.

As is seen in Figs. 1a-c, clay minerals decrease the resistivity of the formation and organic matter in the form of kerogen has an opposite effect to clays causing an increase in the resistivity of rock. Accordingly, two additional components $X$ and $Y$ can be introduced in Eq. (7) to correct the effect of clay and kerogen on formation resistivity response, respectively.

$$
R_{t}=\frac{R_{o}}{S_{w}{ }^{n}}-X+Y
$$

The component $X$ is related to the resistivity decrease caused by the presence of clay minerals. It is simply defined by many workers (e.g. Simondoux, 1963; Pouon and Leveaux, 1971; Clavier and Coates, 1984) as the product of shale volume and shale resistivity. In this regard, considering two parameters would be worth to obtain $X$ as accurate as possible. First, the volume of shale needs to be corrected for organic matter content. Second, accounting a squared form of the volume of shale will be more realistic in the calculation of excess conductivity as a result of shale volume. This is due to the nonlinear relationship between $R_{o}$ and $R_{w}$ in low resistivity rocks (Figs. 1a, c) such as shales which has been discussed in detail in former studies (e.g. Simondoux, 1963; Pouon and Leveaux, 1971). Accordingly, the following equation is proposed for calculation of the component $X$.

$$
X=\left(V_{s h}-V_{k r}\right)^{2} \cdot R_{s h}
$$

It is worth mentioning that if Vsh is calculated from CGR log then kerogen volume is not required to be deducted from shale volume and equation 9 will be simplified as $X=V_{s h}{ }^{2} \cdot R_{s h}$. But the shale volume calculated from GR or SGR log includes organic matter volume as they account for uranium trapped in the kerogen structure in addition to radioactive thorium and potassium of shales. 
In a similar way, the component $Y$ or resistivity increase related to organic matter can be calculated by multiplication of kerogen volume by kerogen resistivity factor $(K R F)$.

$Y=V_{k r}^{2} \cdot K R F$

Detailed explanations on how to calculate KRF are provided in section 4.

Substituting $X$ with Eq. (9) and Y with Eq. (10) in Eq. (8) will give:

$R_{t}=\frac{R_{o}}{S_{w}{ }^{n}}-\left(V_{s h}-V_{k r}\right)^{2} \cdot R_{s h}+\left(V_{k r}\right)^{2} \cdot K R F$

Solving Eq. (11) for $S_{w}$ gives:

$S_{w}{ }^{n}=\frac{R_{o}}{R_{t}+\left[\left(V_{s h}-V_{k r}\right)^{2} \cdot R_{s h}\right]-\left[\left(V_{k r}\right)^{2} \cdot K R F\right]}$

or

$S_{w}=\sqrt[n]{\frac{R_{o}}{R_{t}+\left[\left(V_{s h}-V_{k r}\right)^{2} \cdot R_{s h}\right]-\left[\left(V_{k r}\right)^{2} \cdot K R F\right]}}$

As mentioned earlier, $R_{o}$ is the resistivity of a reservoir rock which is fully saturated with brine $\left(S_{w}=1\right)$. In clean sands or shaly reservoirs, it is usually derived from the reading of resistivity log below the fluids contact where $S_{w}=1$. In the case of gas shale reservoirs, $R_{o}$ is derived from the reading of resistivity logs against the organic lean intervals (Rezaee, 2015). Organic lean intervals can easily be recognized from $\Delta \operatorname{LogR}$ method where there is no separation between porosity and deep resistivity logs in a calibrated standard plot proposed by Passey et al. (1990). This is due to the fact that mineral and fluid components are distributed heterogeneously so that no clear fluid contacts can be depicted in gas shales. Accordingly, it can be said that $R_{s h}=R_{o}$ in gas shales. Taking $n=2$, the final equation for water saturation estimation in gas shale reservoir is expressed as follow.

$S_{w}=\sqrt{\frac{R_{o}}{R_{t}+\left[\left(V_{s h}-V_{k r}\right)^{2} \cdot R_{o}\right]-\left[\left(V_{k r}\right)^{2} \cdot K R F\right]}}$

or in a simplified form as Eq. (15). 
It is worth mentioning that kerogen volume in water saturation equation can be calculated from Eq. (16) and Eq. (17).

$V_{k r}(\%)=\frac{W_{T O C}}{\rho_{T O C}} \cdot \rho_{b}$

$\rho_{\text {TOC }}=0.342 \times V R+0.972$

Total organic carbon (wt\%) can be derived from $\Delta$ LogR method (Passey et al., 1990) or any other suitable methods such as regression equations between well log data and TOC or neural network.

A flowchart showing the computational steps for determination of water saturation in gas shale reservoirs by using the kerogen-clay compensation formula is proposed in Fig. 2.

\section{How to determine kerogen resistivity factor}

As mentioned in section 3, the two main components of the newly introduced equation for water saturation determination in shale gas reservoirs are $X$ and $Y$. Component $\mathrm{X}$ or conductivity excess related to clay minerals presence can be obtained by the multiplication of shale volume by shale resistivity. Shale resistivity is obtained from the average reading of deep resistivity log against a lean shale interval.

The problem, however, remains with the determination of resistivity excess relevant to organic matter presence. As stated in Eq. (10), the component $Y$ is calculated as the product of kerogen volume and kerogen resistivity factor. Considering the infinite resistivity or zero conductivity of pure organic matter it seems impractical to calculate the component $Y$. To tackle the problem, we define a new parameter named kerogen resistivity factor (KRF) rather than using kerogen resistivity, directly. KRF indicates resistivity of dispersed kerogen in a shaly formation causing excess resistivity. Accordingly, we should find a practical way to find resistivity excess of dispersed organic matter. We propose a new chart (Fig. 3a, b) for determination of KRF based on TOC-Resistivity relationship. The proposed chart is prepared based on a geochemical and well logging database from the different gas shale reservoirs around the world. A series of lines indicating the relationship between total organic carbon and deep resistivity (Fig. 3) is obtained covering almost all gas shale formations. Labels appeared on each curve represent KRF (Ohm.m) obtained when the equation of each curve is solved for Rt at TOC $=100 \%$. However, one can determine KRF for a certain formation by 
plotting TOC versus deep resistivity log in Excel sheet and extrapolating the fitting line and reading the formation resistivity at $\mathrm{TOC}=100 \%$.

\section{Application to the Goldwyer Formation}

In this section, water saturation is calculated by using the newly introduced equation and the results have been discussed. The prototype formation of this study is Ordovician Goldwyer shale formation from Dodonea-1 well located in the Canning Basin, Western Australia (Fig. 4). The onshore part of Canning Basin covers an area of about 530,000 squared kilometres in central-northern Western Australia. The offshore extension covers an area of more than 640,000 squared kilometres. The age of the succession in the onshore basin ranges from Ordovician to Cretaceous, but the predominant rock units belong to Paleozoic. In the Early Paleozoic, the Canning Basin has initially developed as an intracratonic sag between the Precambrian Pilbara and Kimberley Basins. The succession of sedimentary rocks in the basin consists of continental to marineshelf, mixed carbonate and clastic sedimentary rocks. In the Ordovician major evaporitic depositional settings were present, with lesser such accumulations in the Silurian and Early Devonian. The proven sourcerock intervals include the Ordovician Nambeet, Willara, Goldwyer, and Carribuddy Formations. In the southern Canning Basin there is potential for gas generation and expulsion from the Permian and preOrdovician carbonaceous shales (Geological Survey of Australia report, 2007). To date, several studies have been carried out in the Canning basin for determination of gas shales reservoir properties and reserve estimation from which McGlade et al. (2012) and Cook et al. (2013) can be mentioned. The estimated original gas in place for the Goldwyer formation is 764 Tcf by the US Energy Information Agency (EIA 2011; Barker 2012). In another study of gas resources in the Canning Basin, the Australian Council of Learned Academies, estimated 409 Tcf of wet gas and 387 Tcf of dry gas in the Goldwyer (Triche and Bahar, 2013). The stratigraphy and petroleum systems of the onshore canning basin is illustrated in Fig. 5.

A full set of well logs along with Rock-Eval pyrolysis data were available over the Goldwyer formation. Well log data were quality controlled for possible measurement errors, borehole conditions and depth shifting issues. TOC was determined by using $\triangle \mathrm{LogR}$ method (Passey el al., 1990) and gamma-ray log was employed for calculation of the volume of shale. KRF and $R_{o}$ were determined as high as $3332 \Omega . \mathrm{m}$. and 10

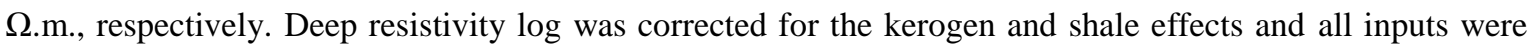
prepared to calculate water saturation by using the new equation. 


\section{Results and discussion}

A full set of well logs from the Goldwyer gas shale formation in well Dodonea-1 were employed to examine the results of the kerogen-clay equation. The components $X$ and $Y$ were calculated based on necessary inputs derived from well log data including total organic carbon, kerogen volume, kerogen resistivity factor and volume of shale. Depth plots showing calculation of resistivity decrease related to clay and resistivity increase related to kerogen for Godwyre formation in Dodonea-1 well are graphically illustrated in Fig. 6a \& Fig. 6b, respectively. As shown in Fig. 6, over the upper intervals of Goldwyer formation (1550 $1600 \mathrm{~m})$ the effect of kerogen is dominant $(X<Y)$ and the combined effect of clay and organic matter will increase $R_{t}$. In the lower interval of $1600-1750 \mathrm{~m}$, the effect of shale is generally dominant leading to decrease in Rt $(X>Y)$. As mentioned earlier, conductivity excess is the product of shale resistivity and volume of shale. In conventional reservoirs shale resistivity is determined from the average reading of the deep resistivity log against a shale interval which is associated with the highest gamma-ray response. However, in gas shales $R_{s h}$ is obtained from the average reading of deep resistivity log against an organic lean shale interval. Organic lean intervals can easily be recognized from $\Delta \operatorname{LogR}$ method where there is no separation between porosity and deep resistivity logs in a standard calibrated plot. Due to the heterogeneous distribution of gas and water in pore space of gas shale, fluid contacts determination seems to be impractical. For this reason, an organic lean shale is treated as fully brine-saturated rock, $S_{w}=1$.

Accordingly, this will result in having the important equality of $R_{s h}=R_{o}$ for the case of gas shale reservoirs. Organic matter in the form of kerogen have an opposite role to shale and cause an increase in the reading of resistivity logs. Resistivity excess is the product of kerogen volume (v/v) and kerogen resistivity factor determined from TOC-Rt plot explained in section 4 of this paper.

It is worth mentioning that the current research tries to provide a simplified model of gas shale formations, however, other conductivity-reducing or increasing minerals can be present adding complexity to the problem. Accordingly, the proposed equation can further be modified to compensate the effect of other minerals on resistivity log.

Unfortunately, it is always hard to take and interpret pressurized core samples from gas shale reservoirs. Due to the presence of irreducible water saturation water may not be produced from some pore systems of gas shales. Water samples taken from gas shales are always not representative of the resistivity of the rock due to the mixing of produced flow back water and free water present in natural fractures. Such problems make it 
difficult and almost impractical to measure water saturation from the core in gas shales. For this reasons, we

used the Archie method to make a comparison with the results of the kerogen-clay equation. However, the proposed approach has a sound logic behind it making one step towards reducing uncertainty in the petrophysical evaluation of gas shale reservoir. Being independent of formation water resistivity and Archie parameters makes it robust, fast and easy to be implemented in gas shale reservoirs.

A comparison between $S_{w}$ determined from simple Archie method ( $\mathrm{Sw}=(\mathrm{Ro} / \mathrm{Rt})^{1 / 2}$, Rezaee, 2015) and the proposed model based on Kerogen-clay conductivity compensation versus depth is graphically illustrated in Fig. 7. Comparing the results shows that Archie method overestimates water saturation specially at high $S_{w}$ ranges. Fig. 8 is a crossplot showing the relationship between $S_{w}$ determined from Archie method and the newly introduced equation. As is seen in Fig.8, the difference between the newly introduced equation and Archie method becomes higher in the higher water saturations. Taking this matter in consideration is important in the economic evaluation of gas shale reservoirs so that using the kerogen-clay equation will provide optimistic volumetric calculations. This will affect recovery methods and field development plans. The ultimate message of this paper is to say "if the resistivity log is corrected for shale and kerogen effects, one step will be made towards a better understanding of water saturation of gas shales”.

After deep resistivity $\log$ is corrected for conductivity-reducing or increasing minerals the remained electrical resistivity can be treated as with the clean formations and a modified version of Archie method, as introduced in this paper, can be employed.

\section{Conclusions}

In this research, an effective equation was proposed for water saturation determination in gas shale formations based upon compensation of kerogen and shale conductivities. The proposed equation was examined by using a full set of well logs and geochemical data from Goldwyer formation in well Dodonea-1 and outstanding results were achieved. The results of this study show that Archie method overestimates water saturation in gas shale formation specially at higher $S_{w}$ ranges. The deviation between the kerogen-clay equation and Archie method grows as water saturation increases. It is expected to have optimistic reserve calculations by using the kerogen-clay model.

The new equation is able to handle both high and low conductivity issues caused by clay and kerogen presence. Being independent of formation water resistivity and Archie parameters make it robust, fast and easy to be implemented in gas shale reservoirs. It is expected to use the kerogen-clay equation for uncertainty reduction in reserve calculation and more successful implementation of reservoir static and dynamic models. 


\section{Nomenclature}

$C_{o}$ : Conductivity of a rock fully saturated with formation water $\left(S_{w}=1\right)$

$C_{t}:$ True formation conductivity when $S_{w}<1$

$C_{w}:$ Conductivity of formation water

$\Delta \log R$ : separation between deep resistivity and porosity logs in a calibrated composite plot $F:$ Formation resistivity factor

$K R F:$ Kerogen resistivity factor

LLD: Deep resistivity log (latero $\log$ )

$n$ : Saturation exponent

$\rho_{b}:$ Bulk density

$\rho_{T O C}:$ Density of organic matter

$R_{o}:$ Resistivity of a rock fully saturated with formation water $\left(S_{w}=1\right)$

$R_{s h}:$ Shale resistivity

$R_{t}:$ True formation resistivity when $S_{w}<1$

$R_{w}:$ Resistivity of formation water

$S_{w}:$ Water saturation

TOC : Total Organic Carbon

$V_{k r}$ : Volume of kerogen

$V R$ : Vitrinite reflectance

$V_{s h}:$ Volume of shale (clay)

$X$ : Resistivity decrease related to clay minerals, resistivity correction factor

$Y:$ Resistivity increase related to kerogen, resistivity correction factor 


\section{References}

Ambrose, R.J., Hartman, R.C., Diaz-Campos, M., Akkutlu, I.Y., Sondergeld, C.H., 2012. Shale gas-in-place calculations Part 1: New pore scale considerations. SPE Journal 17, 219-229.

Archie, G.E. 1942. The electrical resistivity log as an aid in determining some reservoir characteristics. Transactions of the American Institute of Mining and Metallurgical Engineers, 146, 54-62.

Barker, G. 2012. Optimal Shale Gas Evaluation Methods. Oral presentation given at the IBC 3rd Annual Gas Shale Conference, Singapore, 29 November 2012.

Bust, V.K., Majid, A.A., Oletu, J.U., Worthingon, P.F., 2013. The petrophysics of shale gas reservoirs: Technical challenges and pragmatic solutions. Petroleum Geoscience 19, 91-103.

Clavier, C., Coates, G., Dumanoir, J., 1984. Theoretical and Experimental Bases for the Dual-Water Model for Interpretation of Shaly Sands. SPE J. 24 (2): 153-168. SPE-6859-PA.

Cook, P., Beck, V., Brereton, D. 2013. Engineering Energy: unconventional gas production. Melbourne, Australia, Report for the Australian Council of Learned Academies (ACOLA).

Geological Survey of Australia and Petroleum and Royalties Division, 2007. Summary of petroleum prospectively, Western Australia 2007: Bonaparte, Bight, Canning, Officer, Perth, Northern Carnarvon, and Southern Carnarvon Basins: Western Australia Geological Survey, 32p.

Energy Information Administration. 2011. World Shale Gas Resources: An Initial Assessment of 14 Regions Outside the United States. Arlington, Virginia, US DOE.

Kale, S.V., Rai, C.S. \& Sondergeld, C.H. 2010. Petrophysical characterization of Barnett Shale. Paper SPE 131770, Society of Petroleum Engineers, Richardson, Texas.

Luffel, D.L., Guidry, F.K., Curtis, J.B. 1992. Evaluation of Devonian shale with new core and log analysis methods. Journal of Petroleum Technology 44, 1192-1197.

Martini, A.M., Walter, L.M. \& McIntosh, J.C. 2008. Identification of microbial and thermogenic gas components from Upper Devonian black shale cores, Illinois and Michigan basins. American Association of Petroleum Geologists Bulletin, 92, 327-339.

McGlade, C., Speirs, J., Sorrell, S. 2012. A Review of Regional and Global Estimates of Unconventional Gas Resources. London, UK, UK Energy Research Centre. 
Mullen, M., Roundtree, R. \& Barree, B. 2007. A composite determination of mechanical rock properties for stimulation design (What to do when you don't have a sonic log). Paper SPE 108139, Society of Petroleum Engineers, Richardson, Texas.

Passey, Q.R., Creaney, S., Kulla, J.B., Moretti, F.J. \& Stroud, J.D. 1990. A practical model for organic richness from porosity and resistivity logs. American Association of Petroleum Geologists Bulletin, 74, 1777-1794.

Poupon, A., Leveaux, J., 1971. Evaluation of Water Saturations in Shaly Formations. The Log Analyst 12 (4).

Ramirez, T.R., Klein, J.D., Bonnie, R.J.M. \& Howard, J.J. 2011. Comparative study of formation evaluation methods for unconventional shale-gas reservoirs: Application to the Haynesville Shale (Texas). Paper SPE 144062, Society of Petroleum Engineers, Richardson, Texas.

Rezaee, R., 2015. Fundamentals of Gas Shale Reservoirs. Wiley press, US, ISBN: 978-1-118-64579-6. $456 \mathrm{p}$.

Simandoux, P., 1963, Dielectric measurements in porous media and application to shaly formation: Revue de L’Institut Français du Pétrole, v. 18, Supplementary Issue, p. 193-215.

Sondergeld, C.H., Newsham, K.E., Comisky, J.T., Rice, M.C., Rai, C.S., 2010. Petrophysical considerations in evaluating and producing shales gas resources. SPE paper 131768, Society of Petroleum Engineers, Richardson, Texas.

Triche, N.E., Bahar, M., 2013. Shale Gas Volumetrics of Unconventional Resource Plays in the Canning Basin, Western Australia. SPE 167078, 1-14

Wang, F.P., Reed, R.M. 2009. Pore networks and fluid flow in gas shales. Paper SPE 124253, Society of Petroleum Engineers, Richardson, Texas.

Waxman, M.H., Smits, L.J.M., 1968. Electrical Conductivities in Oil-Bearing Shaly Sands, Paper 1863-A, Society of Petroleum Engineers Journal June, 107-122.

Zuber, M.D., Williamson, J.R., Hill, D.G., Sawyer, W.K., Frantz, J.H. 2002. A comprehensive reservoir evaluation of a shale reservoir- the New Albany Shale. Paper SPE 77469, Society of Petroleum Engineers, Richardson, Texas. 


\section{Figure captions}

Fig. 1. Proposed model of kerogen and shale effect on formation resistivity factor $\left(\mathrm{C}_{w} / C_{o}\right)$. Shale increases formation conductivity while kerogen has an opposite effect to shale leading to decrease in $\mathrm{c}_{o}$. Three different scenarios can be considered: (a) combined effect of shale and kerogen causes a decrease in formation conductivity, (b) conductivity excess caused by shale is equal to resistivity excess caused by kerogen so that they neutralize each other and a clean formation behaviour is expected and (c) combined effect of shale and kerogen causes an increases in formation conductivity.

Fig. 2. Proposed flowchart of calculating $S_{w}$ by using kerogen-clay compensation model.

Fig. 3. Proposed $T O C$ versus $R_{t}$ chart for determination of Kerogen resistivity factor $(K R F)$ in linear scale (a), semi-log scale (b). Simply plot laboratory derived TOC data versus their corresponding $R_{t}$ values and choose the best fitting curve. Each label value represents $K R F$ (Ohm.m) determined when the equation of that curve is solved for $R_{t} @ \mathrm{TOC}=100 \%$.

Fig. 4. Location map of the Dodonea-1 well in Canning Basin, Western Australia (Geological Survey of Australia report, 2007)

Fig. 5. Stratigraphy and petroleum systems of the onshore canning basin (Geological Survey of Australia report, 2007)

Fig. 6. Plots showing results of resistivity decrease (a) and resistivity increase (b) calculations for Godwyre formation, Dodonea-1 well

Fig. 7. Comparison between $S_{w}$ determined from Archie method and proposed model based on kerogen-clay conductivity compensation

Fig. 8. Crossplot showing the relationship between $S_{w}$ determined from Archie method and proposed model based on Kerogen-clay conductivity compensation 


\title{
A new correlation for water saturation calculation in gas shale reservoirs based on compensation of kerogen-clay conductivity
}

\author{
Ali Kadkhodaie* and Reza Rezaee \\ Department of Petroleum Engineering, Curtin University, Perth, Western Australia
}

\begin{abstract}
Determination of water saturation in gas shale reservoirs is a very challenging issue due to the incomplete understanding of the non-Archie components. Kerogen and clay content are the two main factors controlling the conductivity of gas shales and resistivity log responses. The presence of clays as conductive materials causes excessive conductivity for the rock that result in an overestimation of water saturation calculation. On the other hand, the presence of solid kerogen has an opposite effect to clays and causes reduction of rock conductivity and thus underestimation of water saturation.

In this research, attempts have been made to develop an effective equation for water saturation determination in gas shale reservoirs based on compensation of kerogen and shale conductivities. The new equation is able to handle both high and low conductivity components. The proposed approach makes one step ahead towards reducing uncertainty in the petrophysical evaluation of gas shale reservoirs. Being independent of formation water resistivity and Archie parameters are of the important and effective aspects of the introduced equation in water saturation calculation of gas shale reservoirs.

Finally, the kerogen-clay compensation equation has successfully been applied to the determination of water saturation in the Goldwyer shale formation, Canning basin, Western Australia.
\end{abstract}

Keywords: Water saturation, gas shale reservoirs, kerogen, shale resistivity, total organic carbon

\section{Introduction}

Water saturation $(\mathrm{Sw})$ is a key and a sensitive parameter for hydrocarbon reserve estimation and any overestimation or underestimation will affect economic evaluations of reservoirs and field development plans. Gas shale reservoirs host considerable amounts of natural gas trapped in the form of free gas and

\footnotetext{
* Corresponding author: Tel/Fax: +61892669366

Email addresses: ali.kadkhodaie@ curtin.edu.au (Ali Kadkhodaie), r.rezaee@curtin.edu.au (Reza Rezaee)
} 
adsorbed gas within their pore space. Petrophysical evaluation of rock properties in gas shales is associated parameters need to be introduced in almost all equations (e.g. Zuber et al., 2002; Sondergeld et al., 2010; Kale, et al., 2010; Mullen, 2010; Ramirez et al., 2011; Ambrose et al., 2012; Rezaee, 2015). The complex pore and organic matter network together with adsorbed gas to the surface of kerogen affect the logging tool responses needing to take them into consideration in petrophysical calculations.

In this regard, accurate determination of water saturation plays a very important role in economic evaluations of gas shales. Investigation of the methods of water saturation determination in gas shale reservoirs has received less attention in the literature in comparison to porosity. Non-Archie rules control the fluids saturation of gas shales since clay and kerogen are two additional components affecting water saturation. On the other hand, the key unknown parameter in water saturation determination is formation water resistivity. The complex interaction between the different mineral and fluid components causes local conductivity barriers in a shaly gas reservoir resulting in a variable range of water resistivities. In this context, a highly variable range of water salinities from a few thousand to a few hundred thousand ppm have been reported throughout a single gas shale formation (e.g. Luffel et al., 1992; Martini et al., 2008 and Zuber et al., 2002). Accordingly, setting a constant value for formation water resistivity will result in uncertain estimation of water saturation.

Unlike conventional reservoirs, there is no feasible well testing method to collect formation water sample from shales. Besides, water samples produced from gas shales are always not representative of the resistivity of the rock due to the mixing of produced flow back water and free water present in natural fractures (Wang and Reed, 2009, Bust et al., 2013).

Actually, a shale gas reservoir is a mixture with different contributions of solid clay, solid kerogen, connate water, free water, clay bond-water, free gas and adsorbed gas to the surface of kerogen. What a resistivity tool measures is a reflection of constituent mineral and fluids of gas shales.

The current research proposes an effective equation for quantification of water saturation in shale gas reservoirs which is independent of water resistivity and Archie parameters. It accounts for conductivity increase or decrease by the presence of conductive or insulator components within shale in water saturation determination equation. 


\section{Developing a new formula for $\mathrm{Sw}$ determination}

The new equation introduced is a derivation of Archie's law developed for clean sand formations (Archie, 1942). According to Archie's law, the ratio of the conductivity of formation water (brine) to the conductivity of a rock fully saturated with that water is a constant value called formation factor (Fig. 1a).

$$
F=\frac{C_{w}}{C_{o}}
$$

or in terms of resistivity formation factor can be expressed as follows:

$F=\frac{R_{o}}{R_{w}}$

Rearranging equation 1 and solving it for $C_{o}$ gives:

$C_{o}=\frac{C_{w}}{F}$

Eq. 3 can be considered for hydrocarbon zone by introducing water saturation to the formula and replacing $C_{o}$ by $C_{t}$ as follows:

$C_{t}=\frac{C_{w}}{F} S_{w}{ }^{n}$

Eq. (4) can be rearranged as:

$$
R_{t} \cdot S_{w}{ }^{n}=F \cdot R_{w}
$$

if $F$ in Eq. (5) is substituted with $F$ in Eq. (2) then:

$$
R_{t} \cdot S_{w}{ }^{n}=R_{o}
$$

Eq. (6) can be rearranged as:

$$
R_{t}=\frac{R_{o}}{S_{w}^{n}}
$$

Eq. (7) is actually an alternative way for representation of the popular Archie formula in a clean formation which is independent of pore water resistivity and Archie parameters (quick look formula). In shaly 
formations, the presence of clay causes excessive conductivity (Fig. 1). In this regard, some other equations proposed for correction of shale effect or conductivity increase in water saturation equation (e.g. Simondoux, 1963; Waxman and Smith, 1968; Pouon and Leveaux, 1971; Clavier and Coates, 1984).

A gas shale reservoir can be treated as a high clay content and organic-rich siliciclastic or carbonate rock. In this context, all equations used for determination of water saturation in shaly formations can be considered after applying necessary corrections for the presence of organic matter.

As is seen in Figs. 1a-c, clay minerals decrease the resistivity of the formation and organic matter in the form of kerogen has an opposite effect to clays causing an increase in the resistivity of rock. Accordingly, two additional components $X$ and $Y$ can be introduced in Eq. (7) to correct the effect of clay and kerogen on formation resistivity response, respectively.

$$
R_{t}=\frac{R_{o}}{S_{w}{ }^{n}}-X+Y
$$

The component $X$ is related to the resistivity decrease caused by the presence of clay minerals. It is simply defined by many workers (e.g. Simondoux, 1963; Pouon and Leveaux, 1971; Clavier and Coates, 1984) as the product of shale volume and shale resistivity. In this regard, considering two parameters would be worth to obtain $X$ as accurate as possible. First, the volume of shale needs to be corrected for organic matter content. Second, accounting a squared form of the volume of shale will be more realistic in the calculation of excess conductivity as a result of shale volume. This is due to the nonlinear relationship between $R_{o}$ and $R_{w}$ in low resistivity rocks (Figs. 1a, c) such as shales which has been discussed in detail in former studies (e.g. Simondoux, 1963; Pouon and Leveaux, 1971). Accordingly, the following equation is proposed for calculation of the component $X$.

$$
X=\left(V_{s h}-V_{k r}\right)^{2} \cdot R_{s h}
$$

It is worth mentioning that if Vsh is calculated from CGR log then kerogen volume is not required to be deducted from shale volume and equation 9 will be simplified as $X=V_{s h}{ }^{2} \cdot R_{s h}$. But the shale volume calculated from GR or SGR log includes organic matter volume as they account for uranium trapped in the kerogen structure in addition to radioactive thorium and potassium of shales. 
In a similar way, the component $Y$ or resistivity increase related to organic matter can be calculated by multiplication of kerogen volume by kerogen resistivity factor $(K R F)$.

$Y=V_{k r}^{2} \cdot K R F$

Detailed explanations on how to calculate KRF are provided in section 4.

Substituting $X$ with Eq. (9) and Y with Eq. (10) in Eq. (8) will give:

$R_{t}=\frac{R_{o}}{S_{w}{ }^{n}}-\left(V_{s h}-V_{k r}\right)^{2} \cdot R_{s h}+\left(V_{k r}\right)^{2} \cdot K R F$

Solving Eq. (11) for $S_{w}$ gives:

$S_{w}{ }^{n}=\frac{R_{o}}{R_{t}+\left[\left(V_{s h}-V_{k r}\right)^{2} \cdot R_{s h}\right]-\left[\left(V_{k r}\right)^{2} \cdot K R F\right]}$

or

$S_{w}=\sqrt[n]{\frac{R_{o}}{R_{t}+\left[\left(V_{s h}-V_{k r}\right)^{2} \cdot R_{s h}\right]-\left[\left(V_{k r}\right)^{2} \cdot K R F\right]}}$

As mentioned earlier, $R_{o}$ is the resistivity of a reservoir rock which is fully saturated with brine $\left(S_{w}=1\right)$. In clean sands or shaly reservoirs, it is usually derived from the reading of resistivity log below the fluids contact where $S_{w}=1$. In the case of gas shale reservoirs, $R_{o}$ is derived from the reading of resistivity logs against the organic lean intervals (Rezaee, 2015). Organic lean intervals can easily be recognized from $\Delta \operatorname{LogR}$ method where there is no separation between porosity and deep resistivity logs in a calibrated standard plot proposed by Passey et al. (1990). This is due to the fact that mineral and fluid components are distributed heterogeneously so that no clear fluid contacts can be depicted in gas shales. Accordingly, it can be said that $R_{s h}=R_{o}$ in gas shales. Taking $n=2$, the final equation for water saturation estimation in gas shale reservoir is expressed as follow.

$S_{w}=\sqrt{\frac{R_{o}}{R_{t}+\left[\left(V_{s h}-V_{k r}\right)^{2} \cdot R_{o}\right]-\left[\left(V_{k r}\right)^{2} \cdot K R F\right]}}$

or in a simplified form as Eq. (15). 
It is worth mentioning that kerogen volume in water saturation equation can be calculated from Eq. (16) and Eq. (17).

$V_{k r}(\%)=\frac{W_{T O C}}{\rho_{T O C}} \cdot \rho_{b}$

$\rho_{\text {TOC }}=0.342 \times V R+0.972$

Total organic carbon (wt\%) can be derived from $\Delta$ LogR method (Passey et al., 1990) or any other suitable methods such as regression equations between well log data and TOC or neural network.

A flowchart showing the computational steps for determination of water saturation in gas shale reservoirs by using the kerogen-clay compensation formula is proposed in Fig. 2.

\section{How to determine kerogen resistivity factor}

As mentioned in section 3, the two main components of the newly introduced equation for water saturation determination in shale gas reservoirs are $X$ and $Y$. Component $\mathrm{X}$ or conductivity excess related to clay minerals presence can be obtained by the multiplication of shale volume by shale resistivity. Shale resistivity is obtained from the average reading of deep resistivity log against a lean shale interval.

The problem, however, remains with the determination of resistivity excess relevant to organic matter presence. As stated in Eq. (10), the component $Y$ is calculated as the product of kerogen volume and kerogen resistivity factor. Considering the infinite resistivity or zero conductivity of pure organic matter it seems impractical to calculate the component $Y$. To tackle the problem, we define a new parameter named kerogen resistivity factor (KRF) rather than using kerogen resistivity, directly. KRF indicates resistivity of dispersed kerogen in a shaly formation causing excess resistivity. Accordingly, we should find a practical way to find resistivity excess of dispersed organic matter. We propose a new chart (Fig. 3a, b) for determination of KRF based on TOC-Resistivity relationship. The proposed chart is prepared based on a geochemical and well logging database from the different gas shale reservoirs around the world. A series of lines indicating the relationship between total organic carbon and deep resistivity (Fig. 3) is obtained covering almost all gas shale formations. Labels appeared on each curve represent KRF (Ohm.m) obtained when the equation of each curve is solved for Rt at TOC $=100 \%$. However, one can determine KRF for a certain formation by 
plotting TOC versus deep resistivity log in Excel sheet and extrapolating the fitting line and reading the formation resistivity at $\mathrm{TOC}=100 \%$.

\section{Application to the Goldwyer Formation}

In this section, water saturation is calculated by using the newly introduced equation and the results have been discussed. The prototype formation of this study is Ordovician Goldwyer shale formation from Dodonea-1 well located in the Canning Basin, Western Australia (Fig. 4). The onshore part of Canning Basin covers an area of about 530,000 squared kilometres in central-northern Western Australia. The offshore extension covers an area of more than 640,000 squared kilometres. The age of the succession in the onshore basin ranges from Ordovician to Cretaceous, but the predominant rock units belong to Paleozoic. In the Early Paleozoic, the Canning Basin has initially developed as an intracratonic sag between the Precambrian Pilbara and Kimberley Basins. The succession of sedimentary rocks in the basin consists of continental to marineshelf, mixed carbonate and clastic sedimentary rocks. In the Ordovician major evaporitic depositional settings were present, with lesser such accumulations in the Silurian and Early Devonian. The proven sourcerock intervals include the Ordovician Nambeet, Willara, Goldwyer, and Carribuddy Formations. In the southern Canning Basin there is potential for gas generation and expulsion from the Permian and preOrdovician carbonaceous shales (Geological Survey of Australia report, 2007). To date, several studies have been carried out in the Canning basin for determination of gas shales reservoir properties and reserve estimation from which McGlade et al. (2012) and Cook et al. (2013) can be mentioned. The estimated original gas in place for the Goldwyer formation is 764 Tcf by the US Energy Information Agency (EIA 2011; Barker 2012). In another study of gas resources in the Canning Basin, the Australian Council of Learned Academies, estimated 409 Tcf of wet gas and 387 Tcf of dry gas in the Goldwyer (Triche and Bahar, 2013). The stratigraphy and petroleum systems of the onshore canning basin is illustrated in Fig. 5.

A full set of well logs along with Rock-Eval pyrolysis data were available over the Goldwyer formation. Well log data were quality controlled for possible measurement errors, borehole conditions and depth shifting issues. TOC was determined by using $\triangle \mathrm{LogR}$ method (Passey el al., 1990) and gamma-ray log was employed for calculation of the volume of shale. KRF and $R_{o}$ were determined as high as $3332 \Omega . \mathrm{m}$. and 10

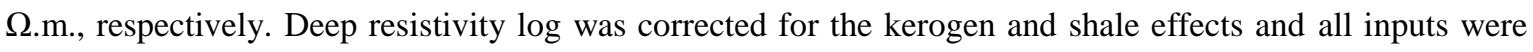
prepared to calculate water saturation by using the new equation. 


\section{Results and discussion}

A full set of well logs from the Goldwyer gas shale formation in well Dodonea-1 were employed to examine the results of the kerogen-clay equation. The components $X$ and $Y$ were calculated based on necessary inputs derived from well log data including total organic carbon, kerogen volume, kerogen resistivity factor and volume of shale. Depth plots showing calculation of resistivity decrease related to clay and resistivity increase related to kerogen for Godwyre formation in Dodonea-1 well are graphically illustrated in Fig. 6a \& Fig. 6b, respectively. As shown in Fig. 6, over the upper intervals of Goldwyer formation (1550 $1600 \mathrm{~m})$ the effect of kerogen is dominant $(X<Y)$ and the combined effect of clay and organic matter will increase $R_{t}$. In the lower interval of $1600-1750 \mathrm{~m}$, the effect of shale is generally dominant leading to decrease in Rt $(X>Y)$. As mentioned earlier, conductivity excess is the product of shale resistivity and volume of shale. In conventional reservoirs shale resistivity is determined from the average reading of the deep resistivity log against a shale interval which is associated with the highest gamma-ray response. However, in gas shales $R_{s h}$ is obtained from the average reading of deep resistivity log against an organic lean shale interval. Organic lean intervals can easily be recognized from $\Delta \operatorname{LogR}$ method where there is no separation between porosity and deep resistivity logs in a standard calibrated plot. Due to the heterogeneous distribution of gas and water in pore space of gas shale, fluid contacts determination seems to be impractical. For this reason, an organic lean shale is treated as fully brine-saturated rock, $S_{w}=1$.

Accordingly, this will result in having the important equality of $R_{s h}=R_{o}$ for the case of gas shale reservoirs. Organic matter in the form of kerogen have an opposite role to shale and cause an increase in the reading of resistivity logs. Resistivity excess is the product of kerogen volume (v/v) and kerogen resistivity factor determined from TOC-Rt plot explained in section 4 of this paper.

It is worth mentioning that the current research tries to provide a simplified model of gas shale formations, however, other conductivity-reducing or increasing minerals can be present adding complexity to the problem. Accordingly, the proposed equation can further be modified to compensate the effect of other minerals on resistivity log.

Unfortunately, it is always hard to take and interpret pressurized core samples from gas shale reservoirs. Due to the presence of irreducible water saturation water may not be produced from some pore systems of gas shales. Water samples taken from gas shales are always not representative of the resistivity of the rock due to the mixing of produced flow back water and free water present in natural fractures. Such problems make it 
difficult and almost impractical to measure water saturation from the core in gas shales. For this reasons, we

used the Archie method to make a comparison with the results of the kerogen-clay equation. However, the proposed approach has a sound logic behind it making one step towards reducing uncertainty in the petrophysical evaluation of gas shale reservoir. Being independent of formation water resistivity and Archie parameters makes it robust, fast and easy to be implemented in gas shale reservoirs.

A comparison between $S_{w}$ determined from simple Archie method ( $\mathrm{Sw}=(\mathrm{Ro} / \mathrm{Rt})^{1 / 2}$, Rezaee, 2015) and the proposed model based on Kerogen-clay conductivity compensation versus depth is graphically illustrated in Fig. 7. Comparing the results shows that Archie method overestimates water saturation specially at high $S_{w}$ ranges. Fig. 8 is a crossplot showing the relationship between $S_{w}$ determined from Archie method and the newly introduced equation. As is seen in Fig.8, the difference between the newly introduced equation and Archie method becomes higher in the higher water saturations. Taking this matter in consideration is important in the economic evaluation of gas shale reservoirs so that using the kerogen-clay equation will provide optimistic volumetric calculations. This will affect recovery methods and field development plans. The ultimate message of this paper is to say "if the resistivity log is corrected for shale and kerogen effects, one step will be made towards a better understanding of water saturation of gas shales".

After deep resistivity $\log$ is corrected for conductivity-reducing or increasing minerals the remained electrical resistivity can be treated as with the clean formations and a modified version of Archie method, as introduced in this paper, can be employed.

\section{Conclusions}

In this research, an effective equation was proposed for water saturation determination in gas shale formations based upon compensation of kerogen and shale conductivities. The proposed equation was examined by using a full set of well logs and geochemical data from Goldwyer formation in well Dodonea-1 and outstanding results were achieved. The results of this study show that Archie method overestimates water saturation in gas shale formation specially at higher $S_{w}$ ranges. The deviation between the kerogen-clay equation and Archie method grows as water saturation increases. It is expected to have optimistic reserve calculations by using the kerogen-clay model.

The new equation is able to handle both high and low conductivity issues caused by clay and kerogen presence. Being independent of formation water resistivity and Archie parameters make it robust, fast and easy to be implemented in gas shale reservoirs. It is expected to use the kerogen-clay equation for uncertainty reduction in reserve calculation and more successful implementation of reservoir static and dynamic models. 


\section{Nomenclature}

$C_{o}$ : Conductivity of a rock fully saturated with formation water $\left(S_{w}=1\right)$

$C_{t}:$ True formation conductivity when $S_{w}<1$

$C_{w}:$ Conductivity of formation water

$\Delta \log R$ : separation between deep resistivity and porosity logs in a calibrated composite plot $F:$ Formation resistivity factor

$K R F:$ Kerogen resistivity factor

LLD: Deep resistivity log (latero $\log$ )

$n$ : Saturation exponent

$\rho_{b}:$ Bulk density

$\rho_{T O C}:$ Density of organic matter

$R_{o}:$ Resistivity of a rock fully saturated with formation water $\left(S_{w}=1\right)$

$R_{s h}:$ Shale resistivity

$R_{t}:$ True formation resistivity when $S_{w}<1$

$R_{w}:$ Resistivity of formation water

$S_{w}:$ Water saturation

TOC : Total Organic Carbon

$V_{k r}$ : Volume of kerogen

$V R$ : Vitrinite reflectance

$V_{s h}:$ Volume of shale (clay)

$X$ : Resistivity decrease related to clay minerals, resistivity correction factor

$Y:$ Resistivity increase related to kerogen, resistivity correction factor 


\section{References}

Ambrose, R.J., Hartman, R.C., Diaz-Campos, M., Akkutlu, I.Y., Sondergeld, C.H., 2012. Shale gas-in-place calculations Part 1: New pore scale considerations. SPE Journal 17, 219-229.

Archie, G.E. 1942. The electrical resistivity log as an aid in determining some reservoir characteristics. Transactions of the American Institute of Mining and Metallurgical Engineers, 146, 54-62.

Barker, G. 2012. Optimal Shale Gas Evaluation Methods. Oral presentation given at the IBC 3rd Annual Gas Shale Conference, Singapore, 29 November 2012.

Bust, V.K., Majid, A.A., Oletu, J.U., Worthingon, P.F., 2013. The petrophysics of shale gas reservoirs: Technical challenges and pragmatic solutions. Petroleum Geoscience 19, 91-103.

Clavier, C., Coates, G., Dumanoir, J., 1984. Theoretical and Experimental Bases for the Dual-Water Model for Interpretation of Shaly Sands. SPE J. 24 (2): 153-168. SPE-6859-PA.

Cook, P., Beck, V., Brereton, D. 2013. Engineering Energy: unconventional gas production. Melbourne, Australia, Report for the Australian Council of Learned Academies (ACOLA).

Geological Survey of Australia and Petroleum and Royalties Division, 2007. Summary of petroleum prospectively, Western Australia 2007: Bonaparte, Bight, Canning, Officer, Perth, Northern Carnarvon, and Southern Carnarvon Basins: Western Australia Geological Survey, 32p.

Energy Information Administration. 2011. World Shale Gas Resources: An Initial Assessment of 14 Regions Outside the United States. Arlington, Virginia, US DOE.

Kale, S.V., Rai, C.S. \& Sondergeld, C.H. 2010. Petrophysical characterization of Barnett Shale. Paper SPE 131770, Society of Petroleum Engineers, Richardson, Texas.

Luffel, D.L., Guidry, F.K., Curtis, J.B. 1992. Evaluation of Devonian shale with new core and log analysis methods. Journal of Petroleum Technology 44, 1192-1197.

Martini, A.M., Walter, L.M. \& McIntosh, J.C. 2008. Identification of microbial and thermogenic gas components from Upper Devonian black shale cores, Illinois and Michigan basins. American Association of Petroleum Geologists Bulletin, 92, 327-339.

McGlade, C., Speirs, J., Sorrell, S. 2012. A Review of Regional and Global Estimates of Unconventional Gas Resources. London, UK, UK Energy Research Centre. 
Mullen, M., Roundtree, R. \& Barree, B. 2007. A composite determination of mechanical rock properties for stimulation design (What to do when you don't have a sonic log). Paper SPE 108139, Society of Petroleum Engineers, Richardson, Texas.

Passey, Q.R., Creaney, S., Kulla, J.B., Moretti, F.J. \& Stroud, J.D. 1990. A practical model for organic richness from porosity and resistivity logs. American Association of Petroleum Geologists Bulletin, 74, 1777-1794.

Poupon, A., Leveaux, J., 1971. Evaluation of Water Saturations in Shaly Formations. The Log Analyst 12 (4).

Ramirez, T.R., Klein, J.D., Bonnie, R.J.M. \& Howard, J.J. 2011. Comparative study of formation evaluation methods for unconventional shale-gas reservoirs: Application to the Haynesville Shale (Texas). Paper SPE 144062, Society of Petroleum Engineers, Richardson, Texas.

Rezaee, R., 2015. Fundamentals of Gas Shale Reservoirs. Wiley press, US, ISBN: 978-1-118-64579-6. $456 \mathrm{p}$.

Simandoux, P., 1963, Dielectric measurements in porous media and application to shaly formation: Revue de L’Institut Français du Pétrole, v. 18, Supplementary Issue, p. 193-215.

Sondergeld, C.H., Newsham, K.E., Comisky, J.T., Rice, M.C., Rai, C.S., 2010. Petrophysical considerations in evaluating and producing shales gas resources. SPE paper 131768, Society of Petroleum Engineers, Richardson, Texas.

Triche, N.E., Bahar, M., 2013. Shale Gas Volumetrics of Unconventional Resource Plays in the Canning Basin, Western Australia. SPE 167078, 1-14

Wang, F.P., Reed, R.M. 2009. Pore networks and fluid flow in gas shales. Paper SPE 124253, Society of Petroleum Engineers, Richardson, Texas.

Waxman, M.H., Smits, L.J.M., 1968. Electrical Conductivities in Oil-Bearing Shaly Sands, Paper 1863-A, Society of Petroleum Engineers Journal June, 107-122.

Zuber, M.D., Williamson, J.R., Hill, D.G., Sawyer, W.K., Frantz, J.H. 2002. A comprehensive reservoir evaluation of a shale reservoir- the New Albany Shale. Paper SPE 77469, Society of Petroleum Engineers, Richardson, Texas. 


\section{Figure captions}

Fig. 1. Proposed model of kerogen and shale effect on formation resistivity factor $\left(\mathrm{C}_{w} / C_{o}\right)$. Shale increases formation conductivity while kerogen has an opposite effect to shale leading to decrease in $\mathrm{c}_{o}$. Three different scenarios can be considered: (a) combined effect of shale and kerogen causes a decrease in formation conductivity, (b) conductivity excess caused by shale is equal to resistivity excess caused by kerogen so that they neutralize each other and a clean formation behaviour is expected and (c) combined effect of shale and kerogen causes an increases in formation conductivity.

Fig. 2. Proposed flowchart of calculating $S_{w}$ by using kerogen-clay compensation model.

Fig. 3. Proposed $T O C$ versus $R_{t}$ chart for determination of Kerogen resistivity factor $(K R F)$ in linear scale (a), semi-log scale (b). Simply plot laboratory derived TOC data versus their corresponding $R_{t}$ values and choose the best fitting curve. Each label value represents $K R F$ (Ohm.m) determined when the equation of that curve is solved for $R_{t} @ \mathrm{TOC}=100 \%$.

Fig. 4. Location map of the Dodonea-1 well in Canning Basin, Western Australia (Geological Survey of Australia report, 2007)

Fig. 5. Stratigraphy and petroleum systems of the onshore canning basin (Geological Survey of Australia report, 2007)

Fig. 6. Plots showing results of resistivity decrease (a) and resistivity increase (b) calculations for Godwyre formation, Dodonea-1 well

Fig. 7. Comparison between $S_{w}$ determined from Archie method and proposed model based on kerogen-clay conductivity compensation

Fig. 8. Crossplot showing the relationship between $S_{w}$ determined from Archie method and proposed model based on Kerogen-clay conductivity compensation 
- A new and effective correlation for Sw calculation in gas shales

- Accounting for the effect of clays on formation conductivity increase

- Accounting for the effect of kerogen on formation conductivity decrease

- Compensation of clay and kerogen conductivity

- Successfully application of the new correlation on Goldwyre gas shale 
(a) Kerogen effect $>$ Shale effect

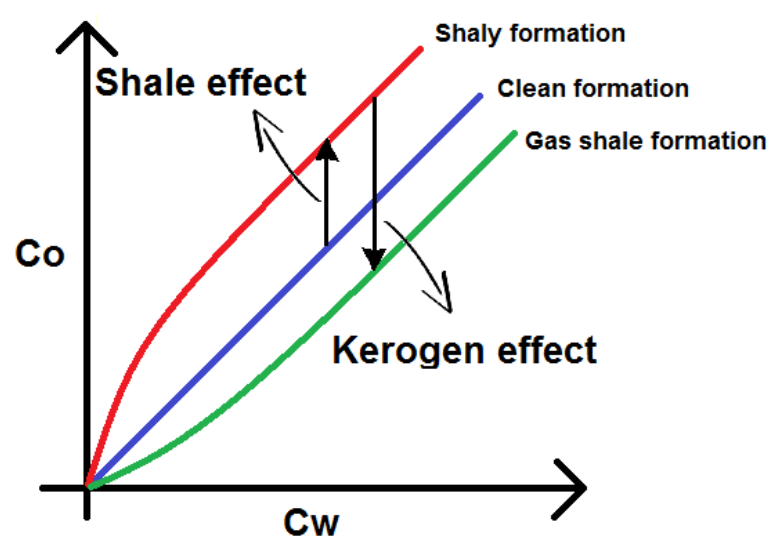

(b) Kerogen effect=shale effect

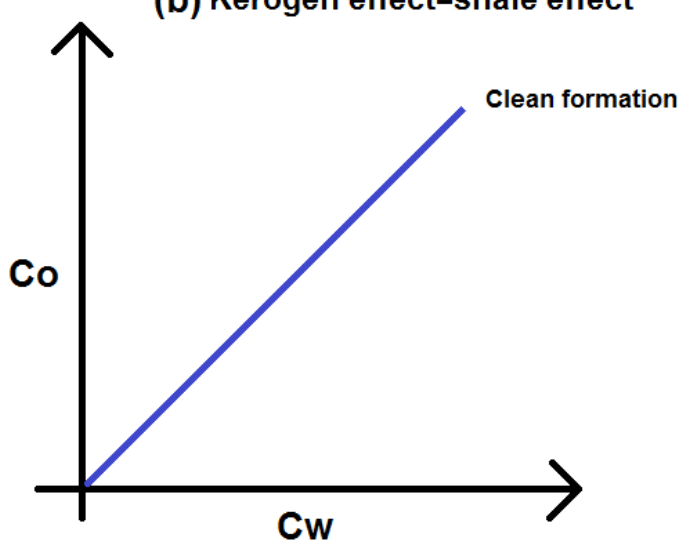

(c) Shale effect > Kerogen effect

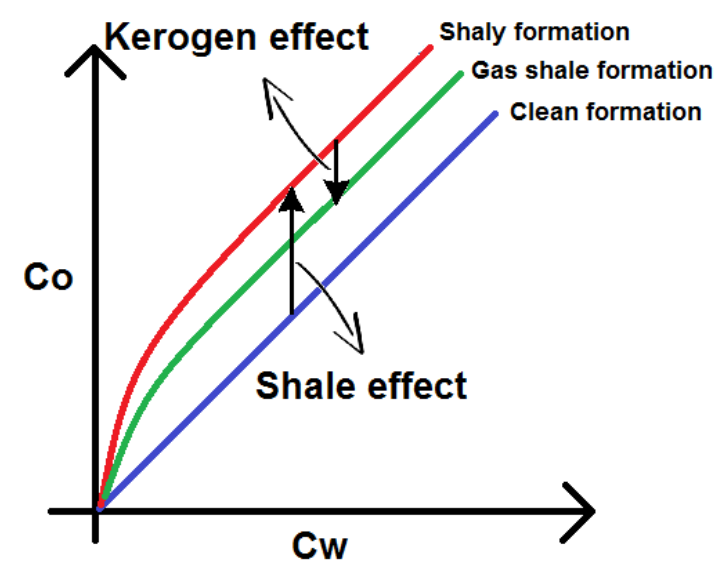

Fig. 1. Proposed model of kerogen and shale effect on formation resistivity factor $\left(\mathrm{C}_{w} / C_{o}\right)$. Shale increases formation conductivity while kerogen has an opposite effect to shale leading to decrease in $\mathrm{c}_{o}$. Three different scenarios can be considered: (a) combined effect of shale and kerogen causes a decrease in formation conductivity, (b) conductivity excess caused by shale is equal to resistivity excess caused by kerogen so that they neutralize each other and a clean formation behaviour is expected and (c) combined effect of shale and kerogen causes an increases in formation conductivity. 


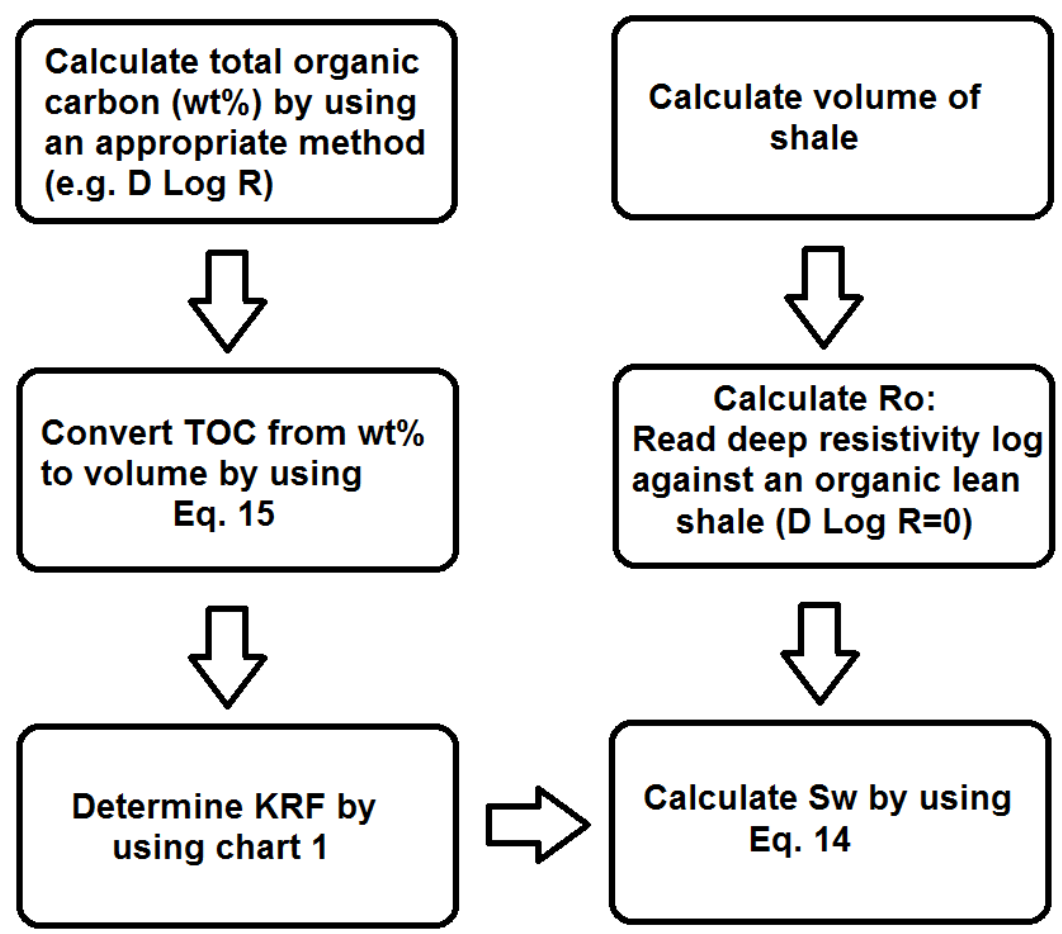

Fig. 2. Proposed flowchart of calculating $S_{w}$ by using kerogen-clay compensation model 
(a)

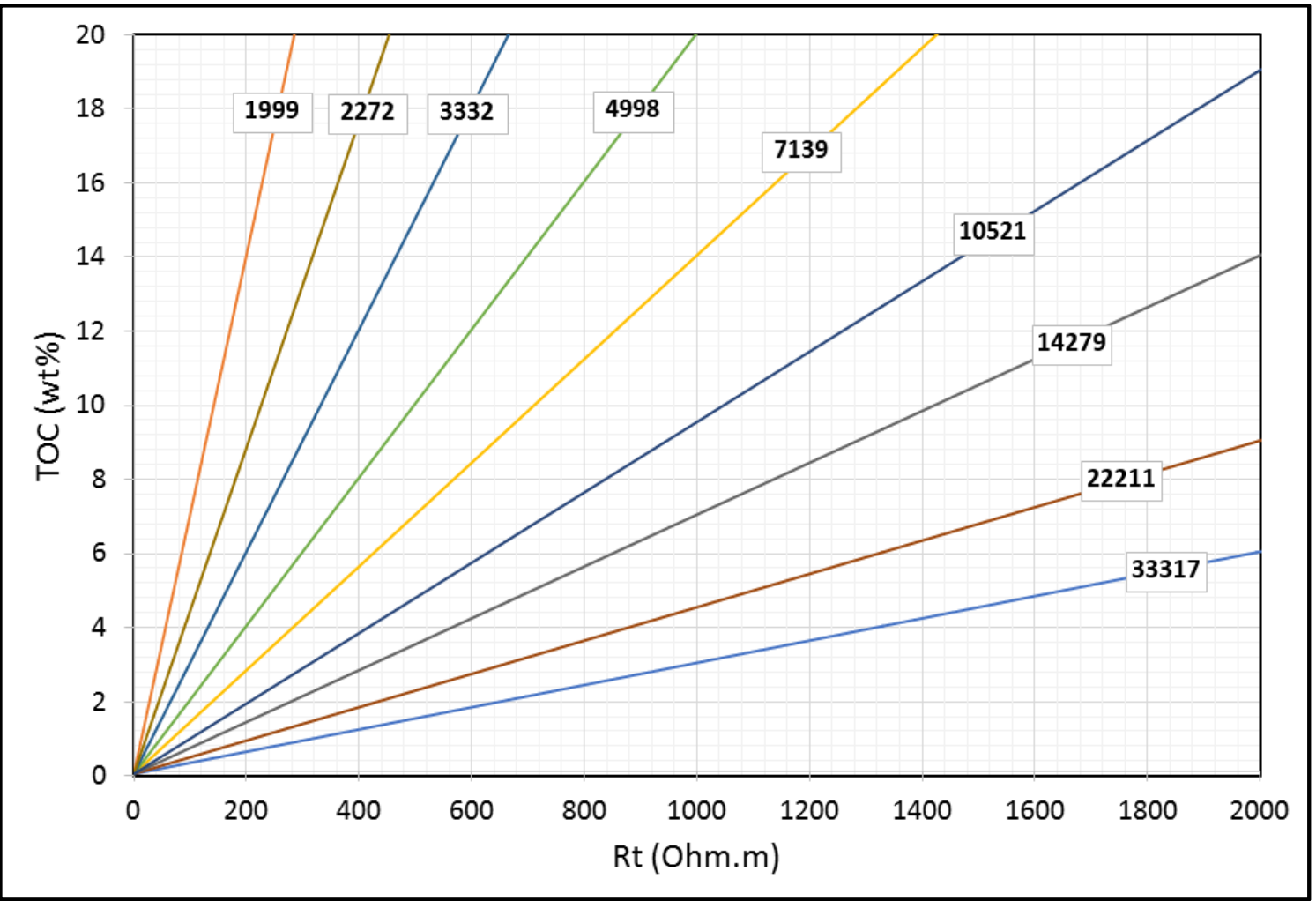

(b)

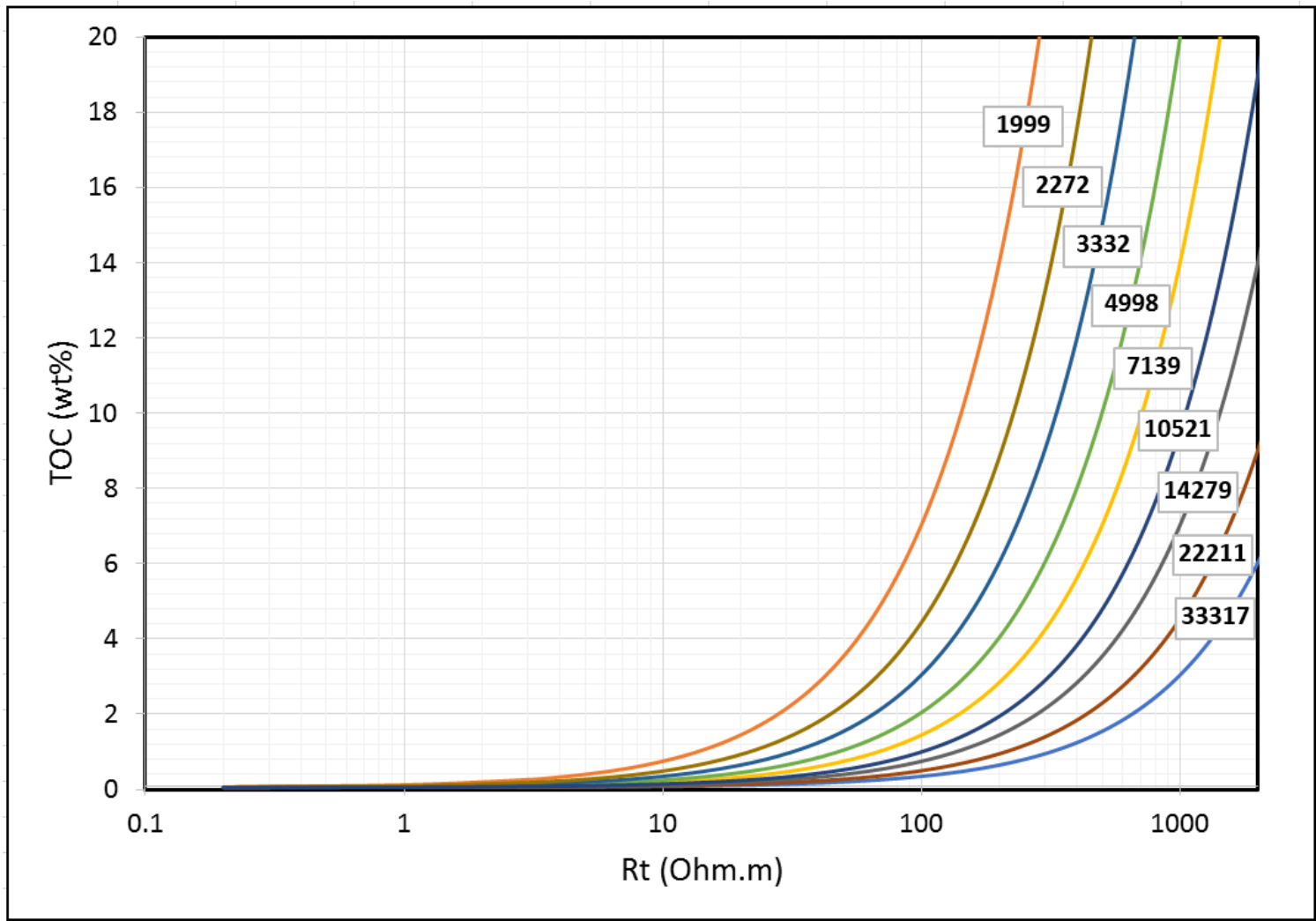

Fig. 3. Proposed TOC versus $R_{t}$ chart for determination of Kerogen resistivity factor $(K R F)$ in linear scale (a), semi-log scale (b). Simply plot laboratory derived TOC data versus their corresponding $R_{t}$ values and choose the best fitting curve. Each label value represents $K R F$ (Ohm.m) determined when equation of that curve is solved for Rt@ TOC=100\%. 


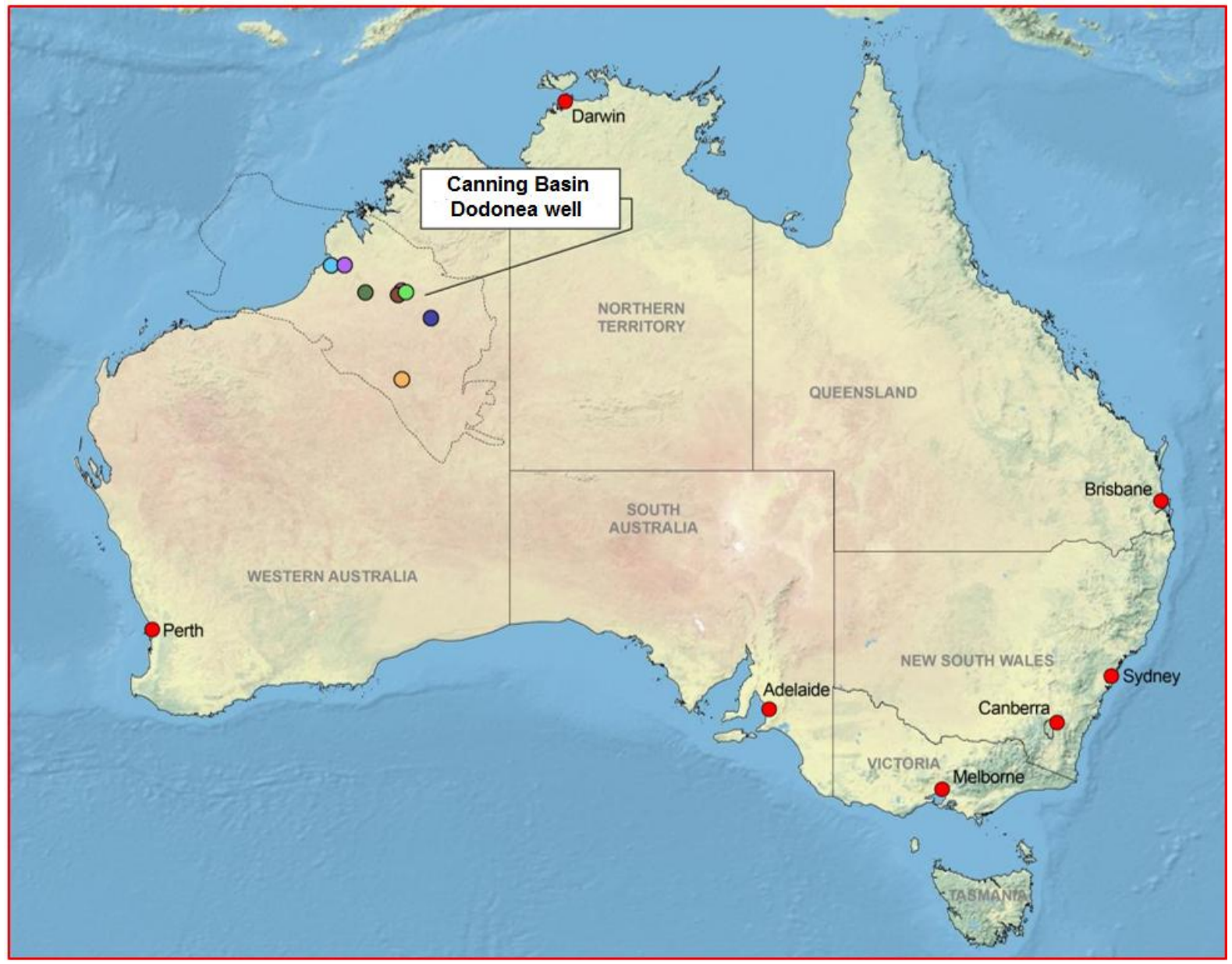

Fig. 4. Location map of the Dodonea-1 well in canning basin, Western Australia (Geological Survey of Australia report, 2007) 


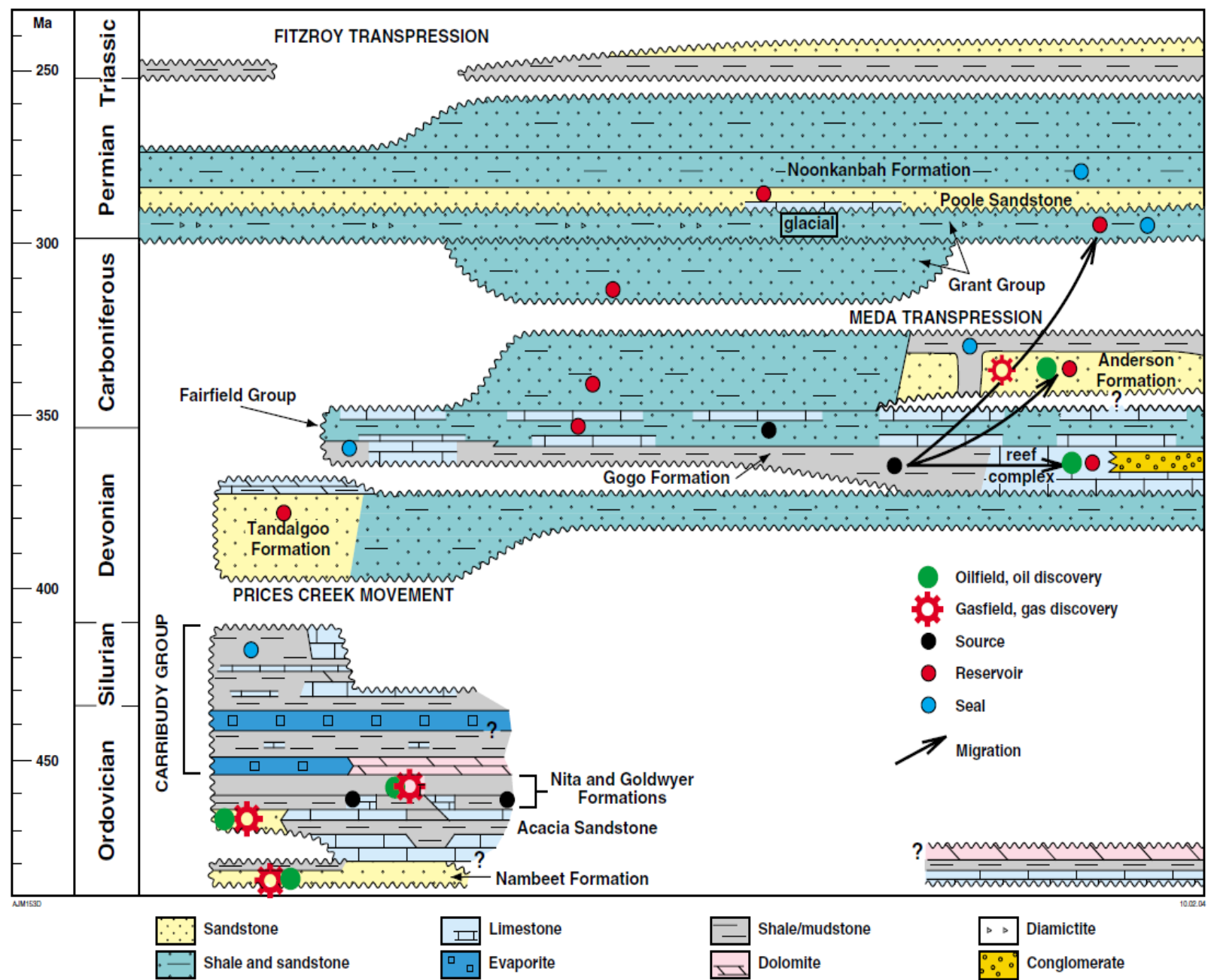

Fig. 5. Stratigraphy and petroleum systems of the onshore canning basin (Geological Survey of Australia report, 2007) 


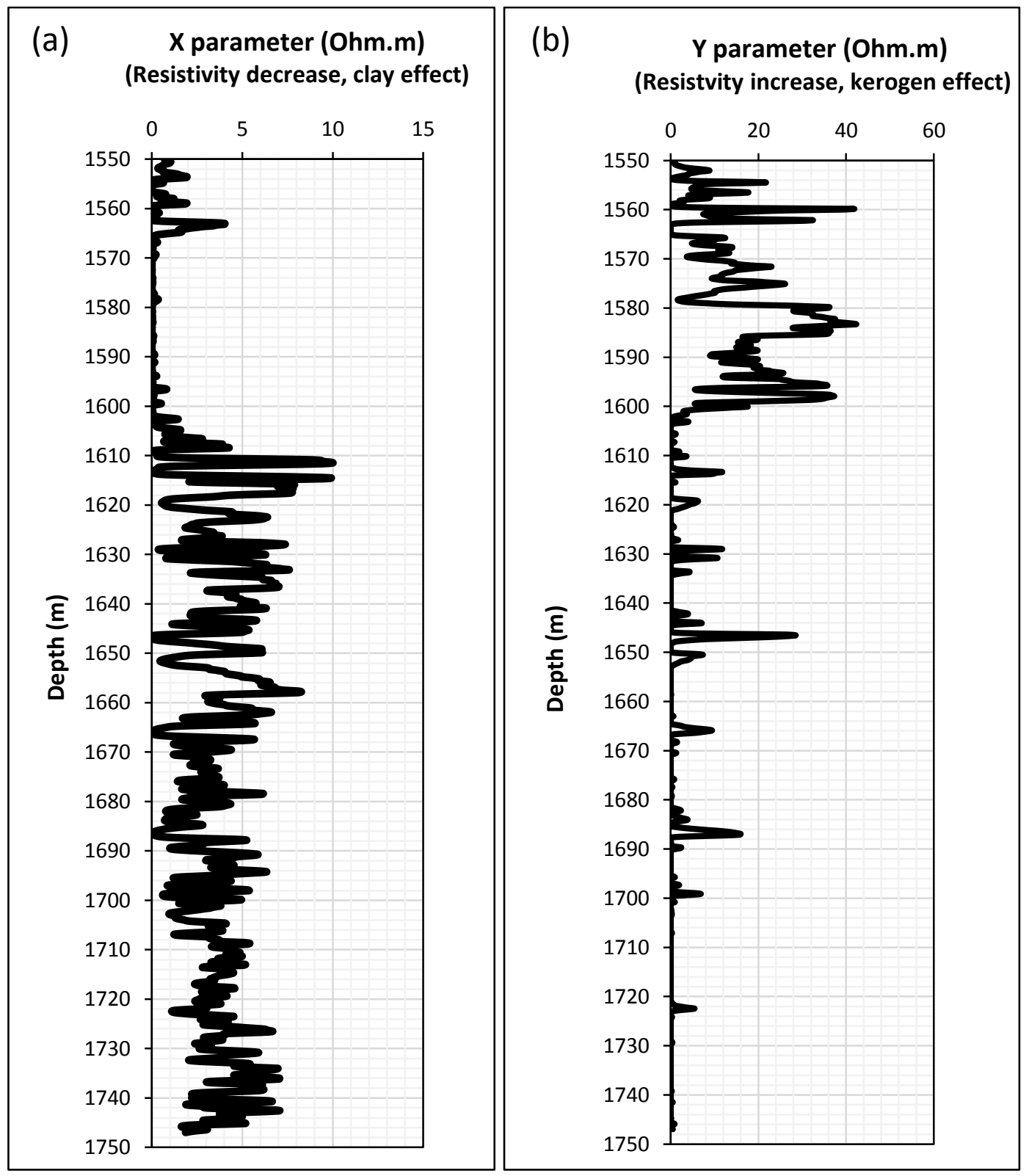

Fig. 6. Plots showing results of resistivity decrease (a) and resistivity increase (b) calculations for Godwyre formation, Dodonea-1 well 


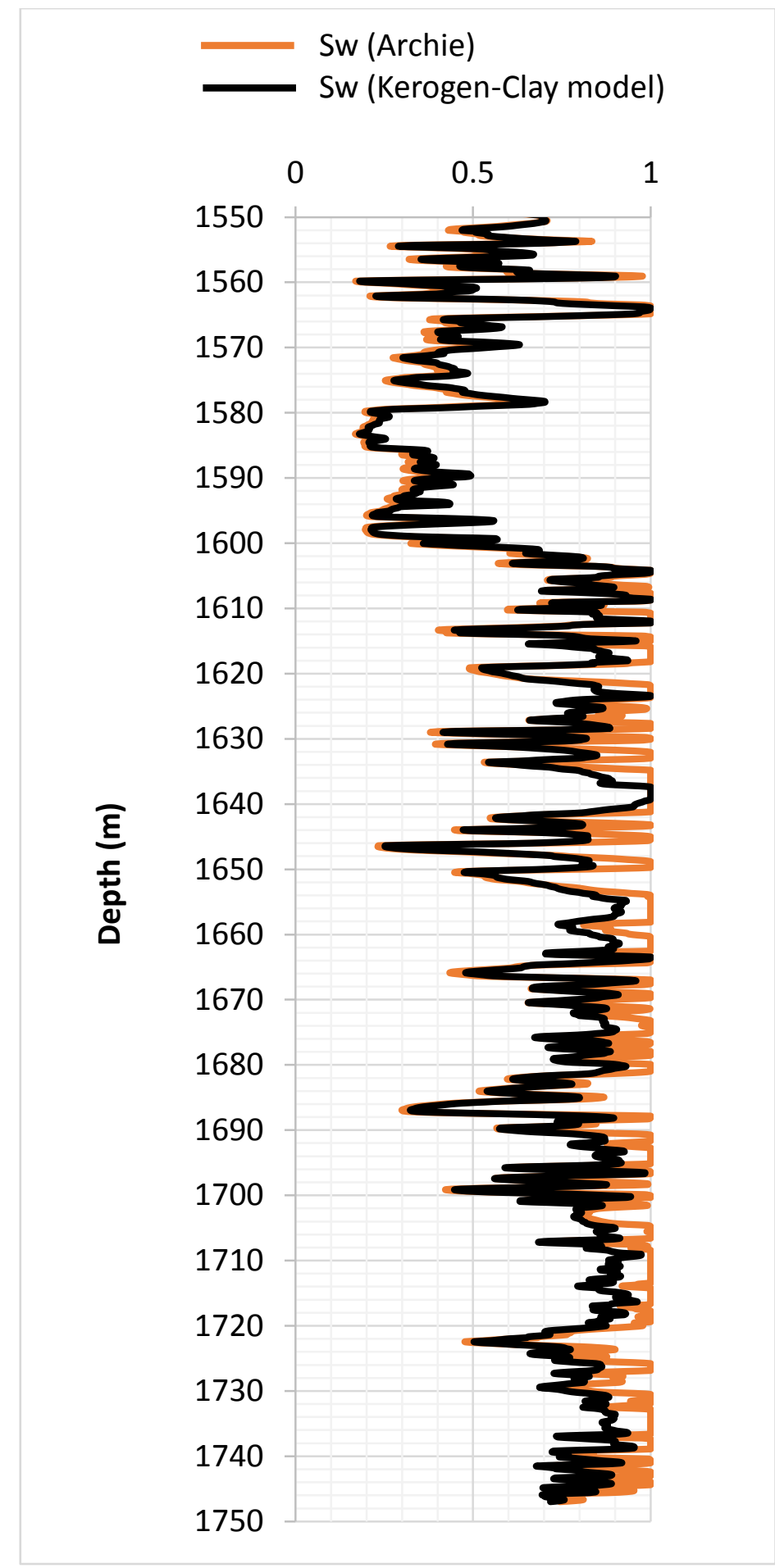

Fig. 7. Comparison between $\mathrm{Sw}$ determined from Archie method and proposed model based on kerogen-clay conductivity compensation 


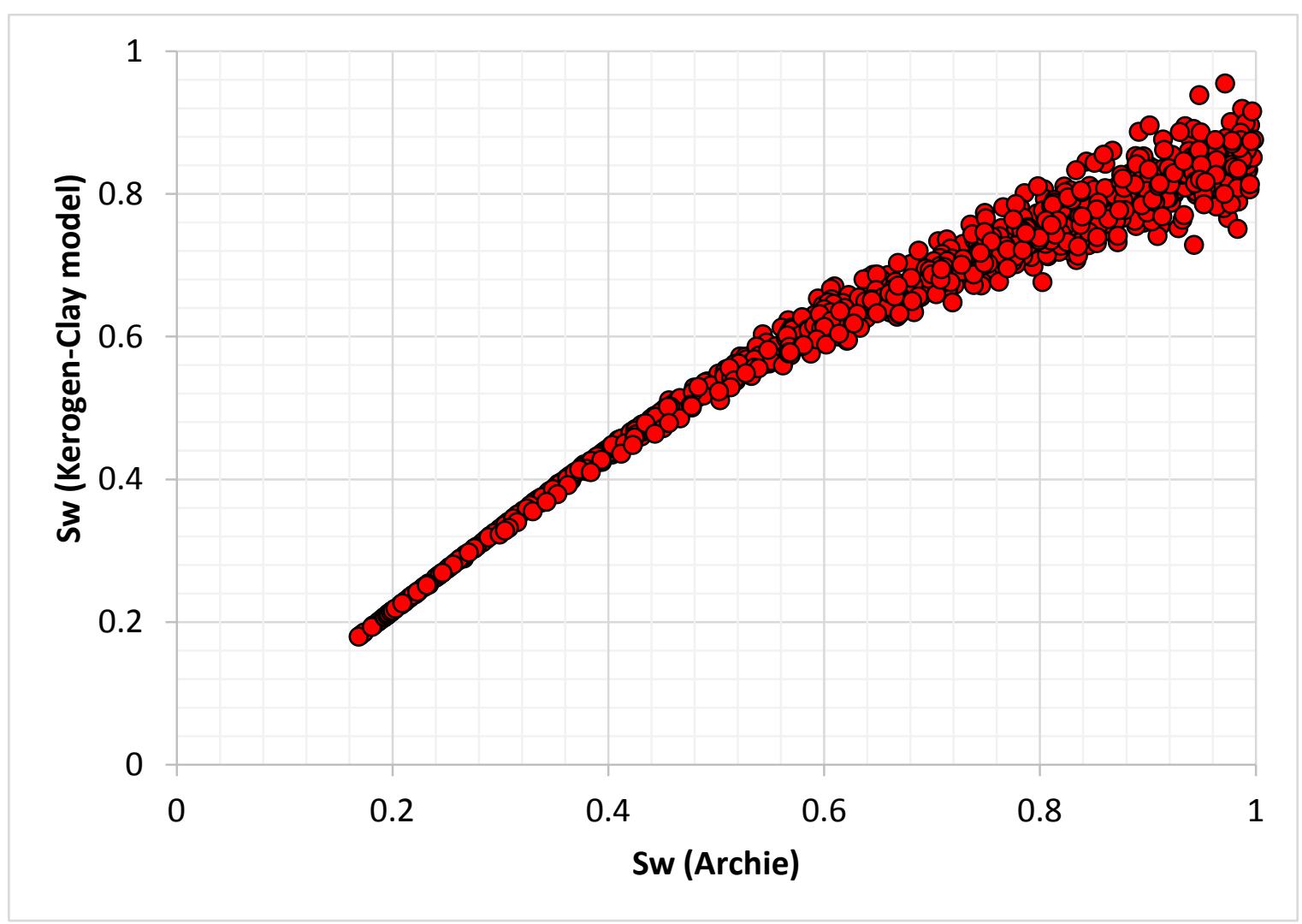

Fig. 8. Crossplot showing the relationship between $\mathrm{Sw}$ determined from Archie method and proposed model based on kerogen-clay conductivity compensation 